\title{
A study on knowledge of animal bite management and rabies immunization among interns of a government medical college in Kolkata
}

\section{Ranadip Chowdhury, Abhijit Mukherjee, Somnath Naskar,} Saibendu Kumar Lahiri

Department of Community Medicine, RG Kar Medical College and Hospital, Kolkata, India

Address for the Correspondence:

Dr. Ranadip Chowdhury, Department of Community Medicine, $3^{\text {rd }}$ Floor Academic Building, RG Kar Medical College and Hospital, 1, Khudiram Bose Sarani, Kolkata - 700 004, India.

E-mail: ranadip84@gmail.com

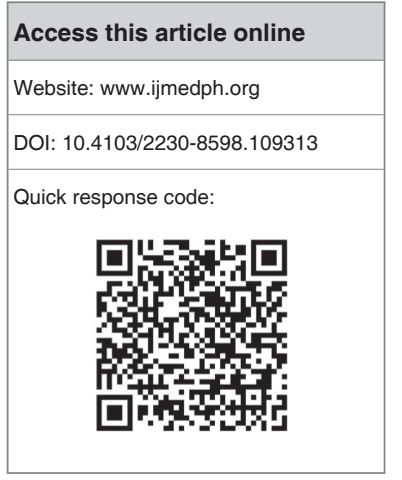

Background: Rabies is a zoonotic disease, transmitted by animal bites, mainly dogs. About $99 \%$ of all human deaths from rabies occur in the developing nations. It is invariably fatal if proper treatment is not instituted promptly. One of the important factors associated with successful treatment is the knowledge of the care giver in the proper management of animal bites and rabies vaccination. Objectives: To assess among the interns of R.G. Kar Medical College, Kolkata: - The knowledge of animal bite wound management. - The knowledge of rabies pre and post-exposure prophylaxis (PEP). Materials and Methods: A predesigned and pretested anonymous questionnaire with structured questions on animal bite and pre- and PEP was distributed among the interns of R.G. Kar Medical College in the month of March 2012. Results: Among the total of 80 interns, $56.3 \%$ and $72.6 \%$ of interns did not categorize bites into single transdermal bite and licks on broken skin as Cat-III wound. $12.5 \%$ of interns were aware of the intradermal route of vaccination. Ten percent of interns could correctly describe the PEP management of Cat-I wounds while $31.2 \%$ of interns thought it was necessary to add rabies immunoglobulin in Cat-II wounds. Conclusion: The results of the study reveal that there are significant gaps in the knowledge regarding the management of animal bite injuries and immunisation.

Key words: Immunization, interns, rabies, rabies immunoglobulin, wound category

\section{INTRODUCTION}

Human rabies continues to be endemic in India. A projected estimate of annual human rabies incidence based on the WHO-sponsored National Multicentric Rabies Survey, 2003, worked out an approximate 20,565 cases per year. ${ }^{[1,2]}$ Since rabies is not a notifiable disease in India and there is no organized surveillance system of human or animal cases, the actual number of deaths may be much higher. ${ }^{[3]}$ The majority of the cases of rabies (about 97\%) are due to bites from rabid dogs, followed by bites from other animals like the cat, cow, monkey, horse, pigs, and camels. ${ }^{[4]}$

According to the WHO, proper post-exposure prophylaxis (PEP) can prevent human rabies completely. ${ }^{[5]}$ Inadequate knowledge regarding the classification of animal bite wounds leading to improper vaccination continue to be seen in other parts of the world and India. ${ }^{[6-10]}$

In a study from China, of the 711 people who died of rabies, $6.3 \%$ were classified as category one, which should have had no risk for rabies, pointing to the fact that knowledge regarding PEP among healthcare staff was not adequate. ${ }^{[6]}$ In their study on dog bite management among medical officers at six dog bite management centers in Pakistan, the researchers expressed a dire need for improved awareness and understanding of dog bite management among health care providers in order to prevent rabies deaths. ${ }^{[7]}$ In addition, there are cases of human rabies reported as a result of stray dog bites treated with vaccines but without immunoglobulin. ${ }^{[8]}$ Studies from third world countries like Tanzania and Turkey have shown a low level of knowledge among physicians regarding zoonotic diseases in general ${ }^{[9]}$ and rabies in particular. ${ }^{[10]}$

The present study was undertaken to identify the knowledge regarding animal bite management and 
pre and PEP including vaccination in special situations, among interns in a medical college in Kolkata, and address the gaps through a CME conducted by an expert in this field.

\section{MATERIALS AND METHODS}

This was a cross-sectional study conducted at the R.G. Kar Medical College and Hospitals. A Continuing Medical Education (CME) was organized for the interns in the department of Community Medicine in the month of March, 2012. Before the CME, the participants were distributed a predesigned and pretested anonymous questionnaire with structured questions on the following aspects of animal bite and pre and PEP:

- Knowledge regarding categorization of animal bite wound

- Knowledge regarding the site, routes, and schedule of PEP

- Knowledge regarding the guidelines of post-exposure prophylaxis

- Knowledge regarding animal bite wound management

- Knowledge regarding rabies immunoglobulin (RIG) administration in routine and special situations.

The CME was followed by an interactive session for the participants with an expert in human rabies. The questionnaire was collected by the researchers. The answers were entered in a computerised version of the questionnaire in Epi Info (version 3.5.4., CDC Atlanta, 2008) and the results analyzed. Inadequacies in knowledge regarding wound management and rabies immunization were broadly classified into two types. Firstly, inadequacies that may lead to an increased risk of human rabies and secondly, inadequacies that cause the unnecessary administration of rabies vaccines and immunoglobulins without an increased risk to the patient.

Examples of the former are the categorization of wounds into lower classes while classification into the higher classes was associated with the second category of inadequate knowledge. Although both categories of inadequacies are to be avoided, any risk of human rabies in the presence of potent vaccines and immunoglobulins in the $21^{\text {st }}$ century is unacceptable.

\section{RESULTS}

A total of 80 interns were included in the study (55 were male and 25 were females). The mean age of the interns was 23.5 years.

Table 1 shows that the majority (95\%) of them correctly classified touching of animals as Category I wounds, while an equal number of interns $(2.5 \%)$ could not classify or classified them into Category II. About $87.5 \%$ of the interns thought that licks on intact skin by rabid animals were Category I, 11.2\% thought they were Category II while $1.2 \%$ could not specify the category. A majority of the interns $(61.2 \%$ and $73.8 \%)$ noted that nibbling of uncovered skin and minor abrasions without bleeding were Cat II wounds. These wounds were classified into a higher category by 10 and $16.2 \%$ of interns, respectively. However, the wounds were categorized into Cat I in $27.5 \%$ and $10 \%$ of interns. Single transdermal bites, licks on broken skin, contamination of mucous membrane with saliva were identified as Category III bites by $43.8 \%, 27.5 \%$, and $75 \%$ of

\begin{tabular}{|c|c|c|c|c|c|}
\hline Wound type & $\begin{array}{l}\text { Cat-I } \\
(\%)\end{array}$ & $\begin{array}{c}\text { Cat-II } \\
(\%)\end{array}$ & $\begin{array}{c}\text { Cat-III } \\
(\%)\end{array}$ & $\begin{array}{c}\text { Donot } \\
\text { know } \\
(\%)\end{array}$ & Guideline \\
\hline $\begin{array}{l}\text { Touching of } \\
\text { animals }\end{array}$ & $76(95)$ & $2(2.5)$ & - & $2(2.5)$ & Cat-I \\
\hline $\begin{array}{l}\text { Licks on intact } \\
\text { skin }\end{array}$ & $70(87.5)$ & $9(11.2)$ & - & $1(1.2)$ & Cat-I \\
\hline $\begin{array}{l}\text { Nibbling of } \\
\text { uncovered skin }\end{array}$ & $22(27.5)$ & $49(61.2)$ & $8(10)$ & $1(1.2)$ & Cat-II \\
\hline $\begin{array}{l}\text { Minor abrasion } \\
\text { without bleeding }\end{array}$ & $8(10)$ & $59(73.8)$ & $13(16.2)$ & - & Cat-II \\
\hline $\begin{array}{l}\text { Single } \\
\text { transdermal bite }\end{array}$ & $10(12.5)$ & $35(43.8)$ & $35(43.8)$ & - & Cat-III \\
\hline $\begin{array}{l}\text { Licks on broken } \\
\text { skin }\end{array}$ & $7(8.8)$ & $51(63.8)$ & $22(27.5)$ & - & Cat-III \\
\hline $\begin{array}{l}\text { Contamination } \\
\text { of mucous } \\
\text { membrane with } \\
\text { saliva }\end{array}$ & $2(2.5)$ & $18(22.5)$ & $60(75)$ & - & Cat-III \\
\hline
\end{tabular}

interns, respectively. The percentage of internees who classified these lower categories was $56.3 \%, 72.8 \%$, and $25 \%$, respectively.

About three fourths $(73.8 \%)$ of interns knew that the site of vaccination was the deltoid. Both intramuscular and intradermal routes of vaccination were known to $10 \%$. The correct schedule of administration was identified by $41.2 \%$ of the interns. [Table 2].

Only $10 \%$ of the interns in the present study noted the correct recommendations regarding vaccination and immunoglobulin administration in Category I wounds. The percentages were 57.5 for Category II and 85\% for Category III bites. With or without wound management, interns recommended vaccines without RIG in $15 \%$, vaccines with RIG in $2.4 \%$ and RIG alone in $3.7 \%$ of Category I bites. In Category II bites vaccines were not noted in $7.5 \%$ of the answers while unnecessary RIG was recommended in $31.2 \%$ of the responses. Wound management was not thought important by $6.2 \%$ of the interns while $5 \%$ did not recommend RIG for Cat III cases [Table 3].

Table 4 shows that $77(96.2 \%)$ of the interns response regarding wound management, $62(77.5 \%)$ regarding antiseptic use, 67 (83.8\%) regarding suturing, and $60(75 \%)$ regarding cauterisation were in accordance to the guidelines.

Correct knowledge regarding RIG (Equine) and RIG (Human) dose was seen in $15 \%$ and $41.3 \%$ of the responses. Only $22.5 \%$ of the interns recommended the use of ERIG at the wound site while $25 \%$ recommended the use of HRIG at the wound site. The majority of the interns did not know the exact dose or the exact site of ERIG or HRIG administration [Table 5].

According to the responses to questions provided to the interns in the present study, analysis reveals an increased risk of human rabies in $27.3 \%$ from improper categorization of wounds, $26.2 \%$ from improper vaccination site selection, $30 \%$ due to improper route if administration and $30.7 \%$ from improper schedule of vaccine administration. Inadequate wound management and improper 


\begin{tabular}{|c|c|c|c|c|c|c|c|c|c|c|c|}
\hline \multicolumn{4}{|c|}{ Site of vaccination } & \multicolumn{6}{|c|}{ Route of vaccination } & \multicolumn{2}{|c|}{$\begin{array}{l}\text { Schedule of } \\
\text { vaccination }\end{array}$} \\
\hline Deltoid & Abdomen & DK & Guideline & IM & ID & IM/ID & Other & DK & Guideline & Yes & No \\
\hline $59(73.8 \%)$ & $2(2.5 \%)$ & $19(23.8 \%)$ & Deltoid & $46(57.5 \%)$ & $2(2.5 \%)$ & $8(10 \%)$ & $7(8.6 \%)$ & $17(21.2 \%)$ & IM/ID & $33(41.2 \%)$ & $47(58.8 \%)$ \\
\hline
\end{tabular}

Figures in parentheses indicate percentages

\begin{tabular}{|c|c|c|c|c|c|c|c|c|c|c|}
\hline Category & DK (\%) & Nothing (\%) & WM (\%) & V (\%) & RIG (\%) & WM+V (\%) & WM+RIG (\%) & WM+V+RIG (\%) & V+RIG (\%) & Guideline \\
\hline CAT-I & $3(3.8)$ & $8(10)$ & $52(65)$ & $4(5)$ & $2(2.5)$ & $8(10)$ & $1(1.2)$ & $1(1.2)$ & $1(1.2)$ & Nothing, if reliable history \\
\hline CAT-II & $3(3.8)$ & - & $4(5)$ & $2(2.5)$ & - & $46(57.5)$ & - & $20(25)$ & $5(6.2)$ & $\mathrm{WM}+\mathrm{V}$ \\
\hline CAT-III & $3(3.8)$ & - & $2(2.5)$ & - & - & $2(2.5)$ & - & $68(85)$ & $5(6.2)$ & $W M+V+R I G$ \\
\hline
\end{tabular}

$\mathrm{M}=$ Wound management, $\mathrm{V}=$ Vaccine, RIG = Rabies immunoglobulin, Figures in parentheses indicate percentages

\begin{tabular}{|c|c|c|c|}
\hline Domain & Guideline & Yes (\%) & No $(\%)$ \\
\hline $\begin{array}{l}\text { Should the wound be } \\
\text { washed immediately }\end{array}$ & Yes & $77(96.2)$ & $3(3.8)$ \\
\hline $\begin{array}{l}\text { Should antiseptic be applied } \\
\text { in the wound }\end{array}$ & Yes & $62(77.5)$ & $18(22.5)$ \\
\hline Should suturing be applied & No & $13(16.2)$ & $67(83.8)$ \\
\hline Should cauterization be done & No & $20(25)$ & $60(75)$ \\
\hline
\end{tabular}

Figures in parentheses indicate percentages

post-exposure schedule could have increased the risk of human rabies in 16.9 and $37.1 \%$ of cases. Increased risk of human rabies was noted in responses regarding RIG doses and site of administration in 86.2 and $76.2 \%$ of responses [Table 6].

Given the fatality of the disease, any lack of knowledge leading to increased risk of human rabies is unacceptable. Gaps have been found in the use of immunoglobulin with most interns not familiar with the dose and site of immunoglobulin administration. Also knowledge regarding rabies immunisation in special situations was low. The interns, however, erred on the safer side regarding vaccination in most cases of animal bites.

\section{DISCUSSION}

There are about $1.7 \%$ animal bites in India every year, ${ }^{[2]}$ mostly from stray animals. A thorough knowledge regarding the management of animal bites and rabies vaccination is a must for all physicians, in order to prevent the development of human rabies. A group of experts on rabies from seven Asian countries have highlighted a lack of awareness among general practitioners regarding rabies. ${ }^{[11]}$ Studies from India ${ }^{[12]}$ and other countries in South-east Asia ${ }^{[13]}$ have reported high level of knowledge among physicians with regard to vectors, causative organisms, incubation period, mode of transmission, or the case fatality rates of the disease, but very few studies reported on the knowledge of physicians regarding animal bite management and rabies prophylaxis.

The lack of proper knowledge of animal bite management and rabies vaccination can on one hand lead to inadequate vaccinations resulting in increased risk of development of human rabies or unnecessary vaccination and immunoglobulin administration causing unnecessary governmental or out-of-pocket expenses by the patient and possible side effects. Loss of human life from rabies in the $21^{\text {st }}$ century when effective PEP and immunoglobulin are universally available is unacceptable.

The first step in planning any intervention is the assessment of the baseline knowledge regarding the problem. This should be followed by interventions designed to address the deficiencies found. The present questionnaire based study was conducted to identify the gaps in knowledge and the CME was designed to correct the deficiencies and misguided information identified. Interns are the physicians of the future. After graduating from medical school many of the interns will take up jobs at the various governmental healthcare centers and hospitals, corporate or nongovernment hospitals or start their own practices. It was, therefore, thought prudent to target this group for study and intervention.

Overall, the interns participating in the study were not well aware of animal bite management and rabies vaccination. This was probably because the medical college where the study was undertaken does not have an animal bite clinic dealing with animal bite management and vaccinations. Instead patients were referred to specialized centers for treatment. In the absence of animal bite clinics most of the undergraduates would not have had an adequate exposure to animal bite management and rabies vaccinations.

Animal bite cases are frequent at all levels of government and private healthcare delivery in India and a practically oriented teaching of wound management and pre and PEP is necessary at the undergraduate level. Interactive CMEs during internship will also help to address specific knowledge deficiencies. Inadequate knowledge of healthcare personnel will on one hand endanger the life of the patients attending the centers for treatment and increase the healthcare budget of the government on unnecessary vaccines and immunoglobulins on the other. The department of community medicine at the medical colleges should take the initiative to start these clinics to deal with this public health problem.

\section{ACKNOWLEDGMENT}

The authors would like to acknowledge Dr. Sumit Poddar for conducting the CME for the interns. The authors are also grateful to the nonacademic staff of the department of Community Medicine at the R. G. Kar Medical College and Hospital for their help in conducting the CME. 


\begin{tabular}{|c|c|c|c|c|c|c|c|c|c|c|c|}
\hline \multirow{2}{*}{$\begin{array}{l}\text { Type } \\
\text { of RIG }\end{array}$} & \multicolumn{4}{|c|}{ Dose (IU/kg) } & \multicolumn{7}{|c|}{ Site } \\
\hline & DK (\%) & $20(\%)$ & $40(\%)$ & Guideline & DK (\%) & D (\%) & G (\%) & PU (\%) & WS (\%) & WS+G (\%) & Guideline \\
\hline ERIG & $64(80)$ & $4(5)$ & $12(15)$ & 40 & $56(70)$ & $2(2.5)$ & $0(0)$ & $2(2.5)$ & $18(22.5)$ & $2(2.50)$ & WS \\
\hline HRIG & $37(46.2)$ & $33(41.3)$ & $10(12.5)$ & 20 & $30(37.5)$ & $2(2.5)$ & $2(2.5)$ & $2(2.5)$ & $20(25)$ & $24(30)$ & WS \\
\hline
\end{tabular}

Figures in parentheses indicate percentages, ERIG = Equine rabies immunoglobulin, HRIG = Human rabies immunoglobulin, DK = Do not know, D = Deltoid, G = Gluteal, PU = Paraumbilical, WS = Wound site, RIG = Rabies immunoglobulin

\begin{tabular}{lcc}
\multicolumn{3}{l}{$\begin{array}{l}\text { Table 6: Influence of lack of knowledge of } \\
\text { caregivers on the risk of human rabies }\end{array}$} \\
$\begin{array}{lcc}\text { Wrong knowledge } \\
\text { regarding }\end{array}$ & $\begin{array}{c}\text { Patients not } \\
\text { at increased } \\
\text { risk of human } \\
\text { rabies } \boldsymbol{N}(\%)\end{array}$ & $\begin{array}{c}\text { Increased } \\
\text { risk of } \\
\text { human rabies } \\
\boldsymbol{N}(\%)\end{array}$ \\
\hline Categorization of wounds & $407(72.7)$ & $153(27.3)$ \\
Site of vaccination & $59(73.8)$ & $21(26.2)$ \\
Route of vaccination & $56(70.0)$ & $24(30.0)$ \\
Schedule of vaccination & $33(41.3)$ & $47(30.7)$ \\
Postexposure prophylaxis & $103(42.9)$ & $137(37.1)$ \\
Wound management & $266(83.1)$ & $54(16.9)$ \\
Immunoglobulin doses & $22(13.8)$ & $138(86.2)$ \\
Site of immunoglobulin & $38(23.8)$ & $122(76.2)$ \\
administration & & \\
\hline
\end{tabular}

\section{REFERENCES}

1. Association for Prevention and Control of Rabies in India. Assessing burden of rabies in India. Report of a WHO sponsored National Multi-centric Rabies Survey. Bangalore: KIMS; 2004.

2. Sudarshan MK. Assessing burden of rabies in India: WHO sponsored national multicentric rabies survey; 2003. Ind J Com Med 2005;30:100-1.

3. Menezes R. Rabies in India. CMAJ 2008;178:564-6.

4. Bhargava A, Deshmukh R, Ghosh TK, Goswami A, Prasannaraj P, Marfatia SP, et al. Profile and characteristics of animals bites in India. J Assoc Physicians India 1996;44:37-8.

5. Wang ZX. WHO position on rabies vaccine. Int J Biol 2002;25:245-8.

6. Song M, Tang Q, Wang DM, Mo ZJ, Guo SH, Li H, et al. Epidemiological investigations of human rabies in China. BMC Infect Dis 2009;9:210.

7. Salahuddin N, Jamali S, Ibraheem K, Sarda S. Awareness about rabies post exposure prophylaxis in Pakistan among patients and health care workers: Results from an Asian Rabies Expert Bureau study. J Coll Physicians Surg Pak 2011;21:491-4.

8. De Benedictis P, Perboni G, Gentili C, Gaetti L, Zaffanella F, Mutinelli F, et al. Fatal case of human rabies imported to Italy from India highlights the importance of adequate post-exposure prophylaxis, October 2011. Euro Surveill 2012;17:pii=20168. Available from: http://www. eurosurveillance.org/ViewArticle.aspx?Articleld=20168. [Last accessed on 2012 Oct 6].

9. John K, Kazwala R, Mfinanga GS. Knowledge of causes, clinical features and diagnosis of common zoonoses among medical practitioners in Tanzania. BMC Infect Dis 2008;8:162.

10. Goänen I, Soysal A, Topuzog A, Bakir M. Clinical Knowledge and Attitudes of Turkish Physicians toward Rabies Caused by Animal Bites. Jpn J Infect Dis 2011;64:382-90.

11. Dodet $B$. Preventing the incurable: Asian rabies experts advocate rabies control. Vaccine 2006;24:3045-9.

12. Bhalla S. Knowledge and Practice among General Practitioners of Jamnagar city regarding Animal Bite. Indian J Community Med 2005;30:94-6.

13. Shah SF, Jawed M, Nooruddin S, Afzal S, Sajid F, Majeed S, et al. Knowledge and practices among the general practitioners of Karachi regarding dog bite management. J Pak Med Assoc 2009;59:861-4.

How to cite this article: Chowdhury R, Mukherjee A, Naskar S, Lahiri SK. A study on knowledge of animal bite management and rabies immunization among interns of a government medical college in Kolkata. Int J Med Public Health 2013;3:17-20.

Source of Support: Zuventus Healthcare Ltd. Sponsored the CME., Conflict of Interest: None declared. 